\title{
SPECIFICS OF NATURAL FREQUENCY MEASUREMENTS FOR FLOOR VIBRATION
}

\author{
Marina Cerpinska, Martins Irbe \\ Riga Technical University, Latvia \\ marina.cerpinska@rtu.lv, martins.irbe@rtu.lv
}

\begin{abstract}
In this paper, results of dynamic testing of the fitness hall floor are presented. The vibration and frequency response was measured for pre-cast concrete floor located in the office building. Complains of the office workers of excessive vibration resulting from fitness activities in the gym hall motivated this study. Two sources of vibrations - rhythmic activities and individual weightlifting activities - were analysed. Spectrum analysis of concrete floor revealed the natural frequency of the floor being $36-38 \mathrm{~Hz}$, which allows the floor to be classified as high frequency floor. Attenuation of floor vibration after the impact was analysed. Vibration of the floor was confirmed to be a perception issue, not a structural one, and human perception of tolerable vibration is briefly discussed.
\end{abstract}

Keywords: floor vibration serviceability; response spectrum.

\section{Introduction}

This case discusses the in-service floor vibration in the office building resulting from activities in the fitness hall. The study was carried out, because the occupants of the multifunctional office building claimed that vibration disturbs them during the working day.

It is not unusual nowadays to incorporate fitness halls inside the office buildings. Practitioner publications suggest that "investing in health promotion is a way of boosting employee performance and reducing absenteeism" [1]. Sometimes commercial gyms are built in the office buildings just because there is available floor space. Meanwhile, the authority of floor system design claims that it is cost prohibitive to design a floor system that supports both aerobics and offices, because "aerobics class is probably the most severe building floor loading for vibration concerns" [2].

In the recent decades lighter structural members like composite floors, thinner concrete decks and longer beam spans are used for construction. As a result of these trends, many office floors have become more susceptible to vibrations when subjected to dynamic loads [3]. Experts argue that nowadays computer-based offices have less live loads, less paper, bookshelves, and less damping [2; 4]. Therefore today, in addition to the design for strength, vibration serviceability of the floors has become an important concern [5] in the design stage of the building.

All floors and structures vibrate, deflect or move to some extent [6], but the vibration only becomes a problem when it is at acceleration that people can perceive or find annoying. Therefore, the floor vibration criteria have two parts: the floor dynamic response and the human tolerance level [2].

The perception of vibrations for humans has been covered in detail by Sache et al. [7] and Živanović et al. [3]. Researches show that office workers are quite sensitive to vibrations. It was noted in early publication of 1989 that human reaction to vibration is "depending partly on the delicacy of the activity being performed" [8]. The experimental results indicated that a standing person is more sensitive to vibrations than a walking one [9].

The aim of the case study was to measure directly the acceleration, response and resonant frequency of the precast concrete floor caused by different realistic excitation events. Dynamic loading from aerobics and weightlifting activities was considered.

Dynamic loadings from sport activities can be classified as harmonic, periodic, transient, and impulsive [10]. In the fitness halls the following loads occur.

- Periodic loads are caused by dancing and aerobics [10].

- Transient loads occur from walking and running. Floor vibration from footfalls is discussed in [5] and is outside the scope of this article.

- Impulsive loads are caused by single jumps and falling of heavy objects, e.g. weightlifting equipment.

According to the Design Guide [6], the forcing frequency of aerobics class is $2.0-3.5 \mathrm{~Hz}$ for the first harmonic. Similarly, Bachmann et al., quoted by Živanović, defined typical frequency ranges of 
1.6-2.4 Hz for walking, 2.0-3.5 Hz for running, 1.8-3.4 Hz for jumping, 1.5-3.0 Hz for bouncing and 0.4-0.7 Hz for horizontal body swaying while stationary [3].

Although researchers state that floor vibration could experience deliberate synchronisation during aerobic classes [7; 8; 11], the authors, quoted by Živanović, reported that synchronisation above 2.75 $\mathrm{Hz}$ was very difficult to achieve [3].

Single jumps and heel-drop impacts are examples of impulsive loads [10], so the impact from equipment drop could also be classified as impulsive load. The characteristic of the impulsive sources is that "there are only a few occurrences per day and the total duration of the activity is of temporary nature" [12].

\section{Materials and methods}

Procedure for checking floor susceptibility described in [8], p.7.3, was followed for this case study: critical locations were identified to choose the accelerometer mounting points, fundamental natural frequency of vibration estimated and compared to acceptable value. The FFT power spectrum was used for natural frequency analysis.

A vibration measuring set consisted of:

1. measuring sensors, three "Wilcoxon Research" piezo accelerometers, 799M, with sensitivity of $1000 \mathrm{mV} \cdot \mathrm{g}^{-1}( \pm 0.5 \%)$ and frequency range of $0.6-1200 \mathrm{~Hz}( \pm 5 \%)$;

2. signal-conditioning circuitry from "Brüel\&Kjær" with "NEXUS" feeding units;

3. recording and monitoring instrument from "National Instruments" with PXI 1031 platform and "Labview 2015; Sound and vibration suite 2015" software.

The selected case study was performed in the fitness hall, which is located on the second floor of a multipurpose center with office rooms, restaurant and dining hall. The ground floor of the building houses a bank client service center. Overall area of the building is $29908 \mathrm{~m}^{2}$. The building has 29 floors, including two underground levels, and is 120.5 meters high. The office is built of suspended slabs supported by columns. During construction 286 piles were driven into the ground up to 27 meters deep.

Since the locations of aerobics area and weightlifting benches are known, vibration problems of the fitness halls could be classified according to the ISO 10137 guidelines as Class B, where the "action of the vibration source changes in time but can be considered stationary in place" [12]. Therefore, sensors where placed in three locations - near the weightlifting area, close to the weightlifting bench and in the aerobics area.

\section{Results and discussion}

The graphical acceleration-time history from different activities is shown in Fig. 1.

In Fig. 1 the peak amplitude corresponds to the arrival of each successive load. As shown in Fig. 1 (c), during each cycle of periodic impulsive loading there are several cycles of response. This phenomenon occurs when "the natural frequency of the structure is significantly higher than the frequency of impulses" [10].

Peak floor acceleration from jumping was $0.70 \mathrm{~m} \cdot \mathrm{s}^{-2}$, from dropping $24 \mathrm{~kg}$ weight it was $3.45 \mathrm{~m} \cdot \mathrm{s}^{-2}$, from dropping the rod it was $4.03 \mathrm{~m} \cdot \mathrm{s}^{-2}$, and from weightlifting it was $1.13 \mathrm{~m} \cdot \mathrm{s}^{-2}$. To put these values in context, the acceleration of $3.4 \mathrm{~m} \cdot \mathrm{s}^{-2}$ (originally $35 \% \mathrm{~g}$ ) is suggested as the lower limit for the onset of panic, whilst the acceleration limits of 0.39-0.69 m- $\mathrm{s}^{-2}(4-7 \% \mathrm{~g})$ are prescribed for design for rhythmic activities [6]. The highest values of acceleration, which could cause different levels of discomfort, stand for weightlifting activities, not aerobics.

The spectrum analysis confirmed that "the magnitudes of the components decrease as the harmonic order increases, i.e. the first harmonic (or fundamental) is the largest" [5]. The response spectrum of a shock motion or shock spectrum [12] with zoomed first harmonic is presented in Fig. 2. 

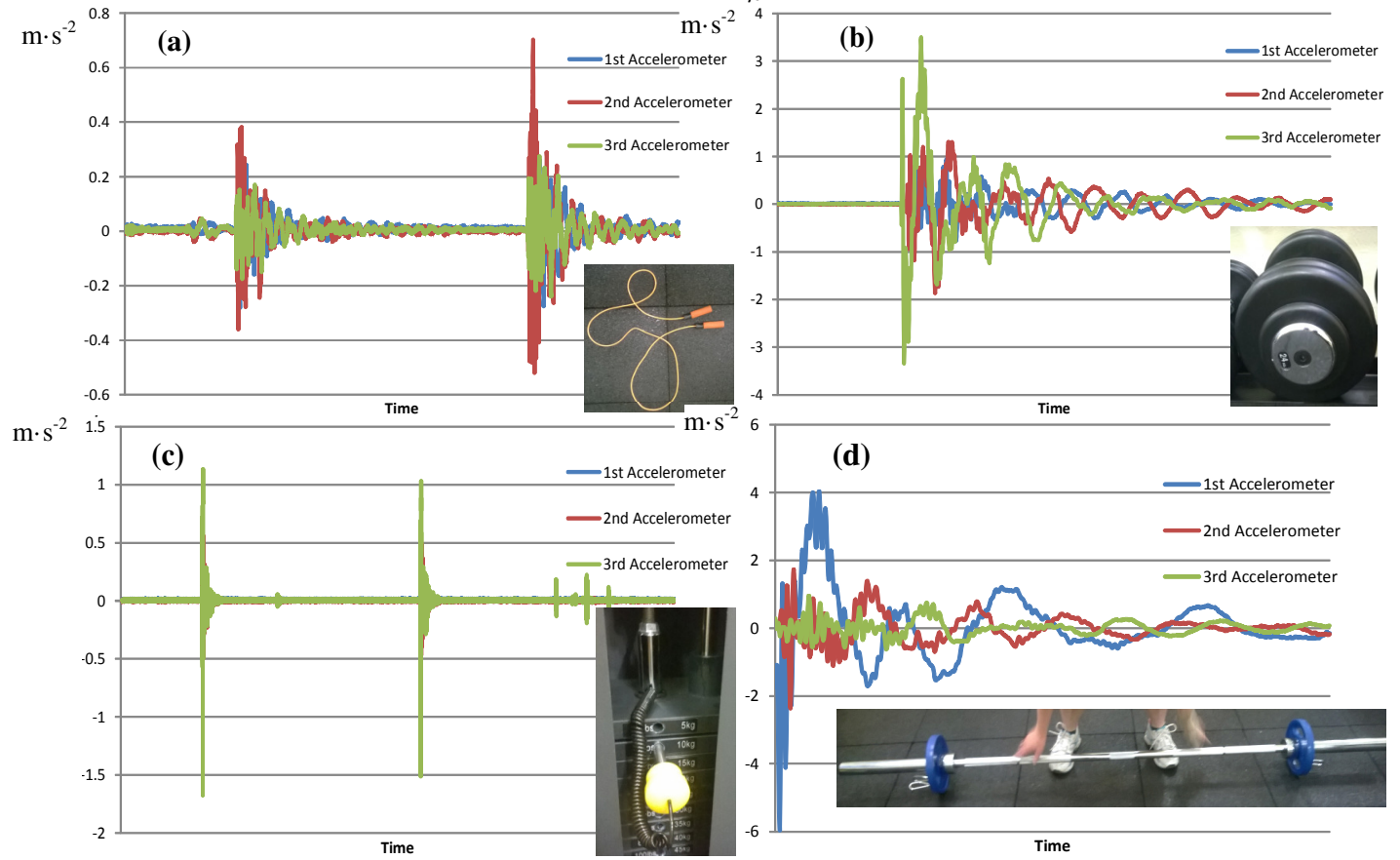

Fig. 1. Dynamic response of the floor from: (a) jumping (b) dropping $24 \mathrm{~kg}$ weight (c) releasing work-out equipment with $10 \mathrm{~kg}$ load (d) dropping a rod with mass $25 \mathrm{~kg}$
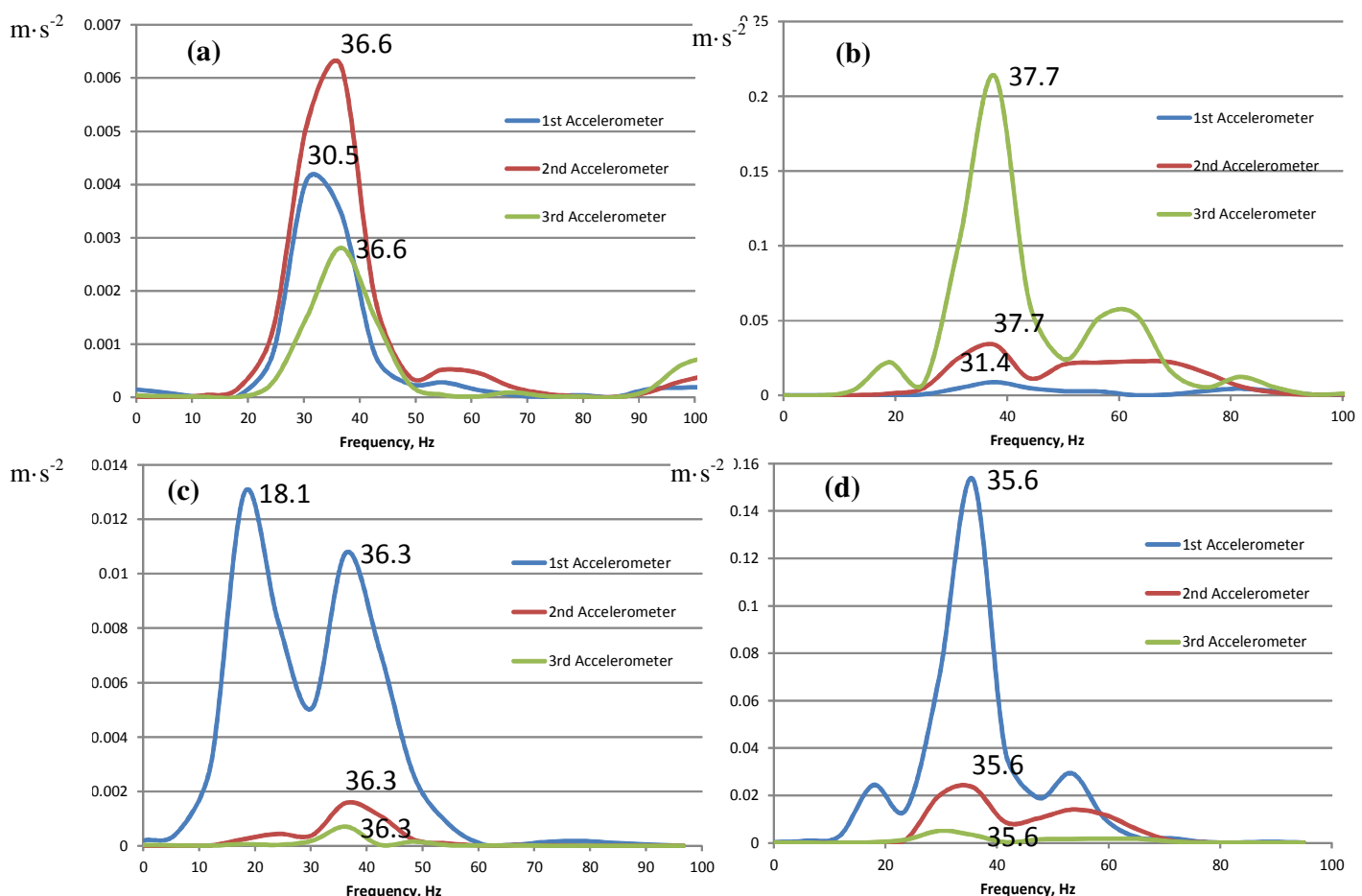

Fig. 2. RMS acceleration response spectrum of the floor with enlarged first harmonic from: (a) jumping (b) dropping $24 \mathrm{~kg}$ weight (c) and (d) dropping a weightlift rod

In the (c) graph spectrum response has a saddle shape similarly as response from vertical force generated by a typical footfall presented by Middleton et al. [5].

According to Fig.2, self-frequency lies in the range from $32 \mathrm{~Hz}$ to $36 \mathrm{~Hz}$. The response spectrum of sensors differs slightly because the transmission path is different for every sensor location. Similarly, the calculated frequency response from Fig.1 for jumping was 3.2 oscillations in $0.1 \mathrm{~s}$, which gives self-frequency of $32 \mathrm{~Hz}$. The calculated frequency response from both from dropping $24 \mathrm{~kg}$ weight and rod was 1.8 oscillations in $0.05 \mathrm{~s}$, which gives self-frequency of $36 \mathrm{~Hz}$. 
The damping ratio of the floor vibration was obtained using the methodology described in [8] and [13]. The damping ratio varied from $8 \%$ to $11 \%$ from readings of the logarithmic decrement function and equalled to $8 \%$ from the spectrum analysis results.

The expected value of the damping ratios for the office buildings ranged from $2 \%$ to $5 \%[4 ; 10]$. The actual value of damping was slightly higher, because elastic pads are used in the fitness hall to absorb the impact from exercising.

Even though aerobics classes are classified as periodic load producers, during this case study both weightlifting and rhythmic activities produced impulsive loading. This is explained by aerobic types preferred by office workers. Yoga, Calanetics and TRX classes dominates over Zumba and Step classes in the chosen fitness hall.

Spectrum analysis of the concrete floor revealed the natural frequency of the floor being 35.6$37.7 \mathrm{~Hz}$, which allows the floor to be classified as high frequency floor and satisfies the requirements for the floor subjected to rhythmic activities to be at least $24 \mathrm{~Hz}$ [5; 14]. The natural frequency is significantly different from low frequency floors, for which the previously reported natural frequencies were close to $3 \mathrm{~Hz}$ [5].

This study highlighted the human subjective response to vibrations, affected by indirect effects like audible noise, structural appearance and activities engaged in [12]. Thus, when office workers have to concentrate on their daily tasks even modest doses of floor vibration can cause discomfort or alarm. In addition, even smallest vibration is alarming when people are working in the office with glass walls, because glass is perceived brittle.

Since the structural vibration criteria are met, the nuisance is attributed to the noise caused by sport activities that the occupants would associate with vibration. In such situations, the best approach is mutual agreement of fitness hall visitors that the weightlifting equipment should be used with care, trying to avoid falling of heavy objects, especially in places where elastic pads do not eliminate noise.

\section{Conclusions}

1. After the in-situ determination of the natural frequency, the studied pre-cast concrete floor can be classified as high frequency floor.

2. The highest values of floor vibration acceleration $\left(3.45-4.03 \mathrm{~m} \cdot \mathrm{s}^{-2}\right)$ in the fitness hall resulted from weightlifting activities, not aerobics.

3. The first harmonic of FFT spectrum for the studied high-frequency floor vibration was around $36 \mathrm{~Hz}$ to $38 \mathrm{~Hz}$. It means that the risk of resonant excitation is low.

4. The damping ratio of the office floors with elastic pads was calculated to be $8 \%$.

5. The obtained values are case specific; nevertheless, they provide information on real pre-cast concrete vibration parameters. It should help designers decide whether the fitness hall should be incorporated into the office building or not.

\section{References}

1. Lowe G.S. Healthy workplaces and productivity: a discussion paper. Minister of Public Works and Government Services, Canada, 2003.

2. Murray T.M. Tips for avoiding office building floor vibrations. Modern steel construction, vol. 41.3, 2001, pp. 24-33.

3. Živanović S., Pavic A., Reynolds P. Vibration serviceability of footbridges under human-induced excitation: a literature review. Journal of Sound and Vibration, vol. 279.1, 2005, pp. 1-74. http://dx.doi.org/10.1016/j.jsv.2004.01.019

4. Hewitt C.M., Murray T.M. Office fit-out and floor vibrations. Modern Steel Construction, vol. 44.4, 2004, pp. 21-23.

5. Middleton C.J., Brownjohn J.M.W. Response of high-frequency floors: A literature review. Engineering Structures, vol. 30, 2009, pp. 1548-1559.

6. Institution of Structural Engineers. Dynamic performance requirements for permanent grandstands subject to crowd action - Interim guidance on assessment and design. The Institution of Structural Engineers, London, November, 2001. 
7. Sachse R., Pavic A., Reynolds P. Human-Structure Dynamic Interaction in Civil Engineering Dynamics: A Literature Review. Shock and Vibration Digest, vol. 35.1, 2003, pp. 3-18.

8. Wyatt T.A. Design guide on the vibration of floors (SCI P076). The Steel Construction Institute, Berkshire, 1989.

9. Mast R.F. Vibration of Precast Prestressed Concrete Floors. PCI journal, vol. 46.6, 2001, pp. 7686.

10. Murray T.M., Allen D.E., Ungar E.E. Design Guide 11, Floor Vibrations Due to Human Activities. American Institute of Steel Construction, 2003.

11. Ebrahimpour A., Sack R.L. A review of vibration serviceability criteria for floor structures. Computers \& Structures, vol. 83.28, 2005, pp. 2488-2494.

12. ISO 10137:2007(en) Bases for design of structures - Serviceability of buildings and walkways against vibrations.

13. Arakawa T., Yamamoto K. Frequencies and damping ratios of a high rise building based on microtremor measurement. Proceedings of "13th World Conference on Earthquake Engineering", 2004.

14. Smith A.L., Hicks S.J., Devine P.J. Design of floors for vibration: A new approach (SCI P354). The Steel Construction Institute, Berkshire, 2007. 